\title{
Ovarian Aging and Hormone Replacement Therapy
}

\author{
Hormonal Levels, Symptoms, and Attitudes of African-American \\ and White Women
}

Kim-Thu C. Pham, MD, MPH, Jeane Ann Grisso, MD, MSc, Ellen W. Freeman, PhD

\begin{abstract}
OBJECTIVES: To characterize reproductive hormone levels, symptoms, and attitudes related to menopause among healthy, menstruating white and African-American women aged 44 to 49 years.
\end{abstract}

DESIGN: Pilot study; cross-sectional survey.

SETTING: Community-based convenience sample of women in the Philadelphia metropolitan area.

PARTICIPANTS: Thirty-three African-American and 35 white women.

MEASUREMENTS: The survey instrument collected demographic data, medical and reproductive history, health practices and behaviors. It included previously validated function, depression, and quality-of-life instruments, and a Menopause Attitude Scale that included two factors, attitudes toward the menopause and attitudes toward medical therapy. Anthropometric measurements were taken at enrollment, and reproductive hormones and daily symptom logs were followed over two menstrual cycles.

MAIN RESULTS: The two groups were comparable in mean age (African-American 46.2 years, white 46.9 years). Serum levels of estradiol, follicle-stimulating hormone, dihydroepiandrosterone-sulfate, and progesterone were comparable. Symptoms were similar in type and frequency. However, the African-American women had significantly more positive attitudes toward menopause, were more likely to rely on family for information about menopause, and were less likely to have been recommended hormone replacement therapy by their physicians. A majority of women in each group expressed satisfaction with the care they had received.

CONCLUSIONS: Perimenopausal African-American and white women have different expectations of menopause and the role of medical care in menopause. This bears directly on women's acceptance of hormone replacement therapy. Conclusions are limited by the small sample size and convenience nature of the study population: further work with larger samples is needed to confirm these apparent differences.

KEY WORDS: menopause; hormone replacement therapy; African-American women, white women, attitudes. J GEN INTERN MED 1997;12:230-236.

$\mathbf{T}$ he decline of ovarian function among women in their thirties and forties has been implicated in the development of physiologic changes that are widely observed a decade later, including body mass and composition, osteoporosis, cardiovascular disease, and psychological distress. Existing data regarding normal reproductive aging derive primarily from white, reproductive-age women with infertility, ${ }^{1}$ postmenopausal women, ${ }^{2}$ or small clinical samples of women seeking medical treatment. ${ }^{3,4}$ It is not known 230 whether the pattern of hormonal changes are similar in African-American and white women. African-American women have higher rates of obesity, cardiovascular disease, and stroke, ${ }^{5,6}$ but lower rates of osteoporosis and vertebral or hip fractures. ${ }^{7,8}$

Several studies have shown that menopausal symptoms vary across cultural groups ${ }^{9,10}$ and socioeconomic strata $^{9,11,12}$ and can be linked to differing societal attitudes toward women's changing roles during and after menopause. ${ }^{13-20}$ The overall prevalence of affective disorders is slightly less in African-American women than white women, ${ }^{21}$ and postmenopausal African-American women are less frequently diagnosed with depression. ${ }^{22}$ Similarly, attitudes toward hormone replacement therapy (HRT) might vary among cultural groups. Most recent investigations of HRT use have involved primarily white women. ${ }^{23-31}$

The aims of this preliminary study were to assess the physiologic and clinical characteristics of healthy premenopausal African-American and white women in their late forties. We sought to characterize mood, behavior, and symptoms in the context of reproductive hormone patterns; attitudes toward menopause and HRT; and perceptions of health care during the late reproductive years. We hypothesized that differences in symptoms would be negligible after adjusting for body mass indices and socioeconomic status. We also hypothesized that differences in attitudes toward menopause and HRT would persist even if symptomatologies were similar.

\section{METHODS}

\section{Subjects}

Using radio, newspaper, and local postings, we assembled a convenience sample of women from the metro-

Received from the Division of General Internal Medicine (KCP,JAG) and Department of Obstetrics and Gynecology, University of Pennsylvania, Philadelphia.

Presented in part at the national meeting of the Society of General Internal Medicine, Washington, DC, May 1996.

Supported in part by the Public Health Services research grant MO1-RRO0040 from the National Institutes of Health, and by the University of Pennsylvania Research Foundation grant 370569.

Address correspondence and reprint requests to Dr. Pham at her current address: Primary Care Unit, Allegheny University Hospital-Medical College of Pennsylvania, 3300 Henry Ave., Philadelphia, PA 19129. 
politan Philadelphia area. Interested women were screened for eligibility by a standardized telephone interview, and enrolled if they were 44 to 49 years of age and had menstruated within the previous 3 months. Exclusion criteria included current HRT or hormonal contraception, hysterectomy or oophorectomy, current psychiatric illness or use of psychotropic medications, use of centrally acting antihypertensive medication, history of diabetes mellitus, liver disease, breast or endometrial cancer, and history of substance or alcohol abuse within the past year.

A total of 210 women volunteered for the study from September 1995 through July 1996. Seventy-nine (38\%) potential participants were excluded on the basis of the above criteria; 57 (27\%) declined to participate; 74 (37 African-American, 37 white) women were enrolled in the study. Of these, $6(8 \%)$ discontinued the study because of initiation of HRT, hysterectomy, or loss to follow-up. Complete data were obtained for 68 (92\%) of the women (35 white, 33 African-American). All procedures and informed consent were conducted in accordance with the ethical standards of the Office of Research Administration, Committee on Studies Involving Human Beings, of the University of Pennsylvania.

\section{Data Collection}

The initial visit, scheduled within 3 to 8 days of the onset of the next menses, consisted of an interview, blood testing, and a brief physical examination. Subjects were given a daily symptom diary to complete at home for the subsequent 2 months and scheduled to return twice more for phlebotomy to assess hormone levels.

\section{Questionnaire}

The questionnaire included age, education, employment, income, and information on general health, health practices, and behavior. The following instruments were incorporated:

The SF-36 Health Survey. This is a 36-item, extensively validated, self-report of physical, social and mental health, ${ }^{32-34}$ which yields 8 subscores on physical and social function, emotional and physical roles, bodily pain, general health and vitality, and mental health.

\section{The Center for Epidemiologic Studies-Depression} Scale. This is a 20-item, extensively validated, self-report scale to screen for depression. ${ }^{35}$ Items are rated from 0 (not at all) to 4 (most of the time) and are summed for a total score (range, 0 to 60 ). Scores greater than or equal to 16 indicate the possibility of clinical depression.

A Quality of Life Questionnaire. Adapted from Endicott et al., this is a 14-item summary of the status of activities, relationships, and physical abilities. ${ }^{36}$ The items are rated from 1 (very poor) to 5 (very good) and are summed for a total score.

A Menopause Attitude Scale. Adapted from previously validated scales by Lieblum and Swartzman, ${ }^{37}$ and Groeneveld et al., ${ }^{38}$ this 10 -item scale addresses medical care in menopause and the general effect of menopause on sexuality and well-being. Three items address attitudes toward medical intervention for menopause; six items address attitudes toward menopause in general. These items are rated from 1 (strongly agree) to 7 (strongly disagree) and summed for the medical and general menopause subscales. A single item rates the relative impact of psychosocial stressors versus physical symptoms on wellbeing. Groeneveld reported clustering of items, eight of which are included in our instrument, into three factors, "disadvantage," "advantage," and "treatment," with Cronbach's $\alpha=0.78,0.65$, and 0.59 , respectively.

\section{Laboratory Measures}

Blood samples were obtained at three points during the study: early follicular phase (days 3-8) for two menstrual cycles, and luteal phase of the first cycle (approximately 14 days following follicular-phase sampling, adjusted for cycle length). Follicular-phase samples were assayed for follicle-stimulating hormone (FSH), estradiol, and dihydroepiandrosterone sulfate (DHEA-s). Progesterone was assayed in the luteal-phase sample. Our calculations indicate that with sample sizes of 30 subjects in each group, we would have greater than $99 \%$ power to detect a difference in estradiol level of $20 \mathrm{pg} / \mathrm{mL}$ between the two groups, and comparable power to detect a clinically significant difference in FSH.

All blood specimens were drawn into glass tubes without anticoagulant; serum was promptly separated and frozen at $-70^{\circ} \mathrm{F}$. Assays were run in batch to minimize assay variability, and control materials were within two standard deviations of previously determined mean values. Estradiol was measured by the assay Coat-a-Count Estradiol (Diagnostic Products Corp., Los Angeles, Calif.), progesterone by Coat-a-Count Progesterone (Diagnostic Products Corp.), and DHEA-s by DHEA-sulfate (Diagnostic Systems Laboratories, Webster, Tex.); all three use competitive radioimmunoassay. The FSH was measured using ACS-180 FSH (Ciba-Corning Diagnostics Corp., Medfield, Mass), which is an automated immunochemiluminescent assay.

\section{Anthropometric Measures}

Body weight (in kilograms) was measured with a calibrated scale, and height (in meters) using a vertical metric ruler. Body-mass index (BMI) ${ }^{39}$ was calculated as $\mathrm{kg} / \mathrm{m}^{2}$.

Waist circumference (measured at one third the distance between xiphoid process and umbilicus, to the nearest centimeter), and hip circumference (measured at $4 \mathrm{~cm}$ below superior anterior iliac spine) were measured using a calibrated tape measure, and used to calculate the waist-to-hip ratio. ${ }^{40}$ 


\section{Menstrual Cycle Information}

Subjects maintained menstrual Daily Symptom Ratings (DSR), a scale modified from one previously validated in African-American and white women with premenstrual syndrome, ${ }^{41}$ over the course of two menstrual cycles. Scores were calculated as the sum of daily ratings from 0 (not present) to 4 (very severe) on 15 commonly associated symptoms: fatigue, feeling out of control, headache, anxiety, joint or muscle pain, irritability, bloating, depression, sleep disturbance, hot flashes, night sweats, forgetfulness, urinary incontinence, dizziness, and vaginal dryness.

\section{Analysis}

Statistical analyses were performed using SAS version 6.11 (SAS Institute, Cary, NC), and JMP version 3.1 (also SAS Institute). Group differences for continuous variables were assessed using means with confidence intervals and Student's $t$-test for independent samples. We used $\chi^{2}$ analysis to assess the interrelationships of dichotomous covariates, and correlations to assess interrelationships of continuous covariates.

Using analysis of covariance the class-by-covariate (saturated model: class [race], covariate [education, income, symptom rating, physician contact], and class-bycovariate) interaction was assessed to determine whether the relation between covariate and response variable was consistent between the two races. For discrete covariates, we used analysis of variance.

\section{RESULTS}

The white women $(n=35)$ and African-American women $(n=33$ ) were comparable in age (mean 46.9 and
46.2 years, respectively), and nearly all were employed (86\% and 94\%) (Table 1). Most women in both groups had completed at least high school; the white women were twice as likely to have completed college or beyond $(72.2 \%$ vs $28.6 \%, p=<.0005)$, and more likely to be married (67\% vs $40 \%, p<.05)$, have been pregnant fewer times (2.6 vs 3.7, $p<.05$ ), and have higher mean household incomes $(\$ 61,300$ vs $\$ 45,000, p<.005)$.

Reproductive histories did not differ in terms of age at menarche, average cycle length, or menstrual irregularity. The white women reported significantly higher rates of diagnosis of ovarian cysts and depression, while the African-American women reported diagnoses of uterine fibromyomata and hypertension more frequently (Table 2). The African-American women had significantly greater BMIs (White $25.0 \mathrm{~kg} / \mathrm{m}^{2}$ vs African-American $30.3 \mathrm{~kg} / \mathrm{m}^{2}, p=$ .0001) and android body fat distribution as indicated by waist-to-hip ratios (whites 0.77 vs African-Americans $0.81, p=.0006)$.

SF-36 scores did not significantly differ except for slightly higher scores in general health and social function subscales by the white women. Although nearly one in five of the white women reported a previous history of treatment or diagnosis of depression, as compared with none of the African-American women, scores on the CES-D, and percentages with scores of 16 or greater, were similar for the African-American women and white women (Table 2). The Quality of Life Questionnaire yielded no significant differences between the two groups.

Only one factor from the Menopause Attitudes Scale, attitudes toward menopause in general, yielded significantly different scores (mean scores, 16.5 for African-Americans vs 19.1 for whites, $p=.02$; Table 3 ). The lower score, reflecting more positive attitudes on items addressing sexuality, physical changes, and well-being, persisted after

Table 1. Demographic Characteristics*

\begin{tabular}{|c|c|c|}
\hline & $\begin{array}{c}\text { Whites } \\
(n=35)\end{array}$ & $\begin{array}{l}\text { African-Americans } \\
\qquad(n=33)\end{array}$ \\
\hline Age, years & $46.9(46.5-47.5)$ & $46.2(45.6-46.7)$ \\
\hline High school & $97.2(91.5-103.0)$ & 100 \\
\hline College & $72.2(56.9-87.6)$ & $28.6(11.7-44.6)$ \\
\hline Married $^{\dagger}$ & $66.7(50.5-82.8)$ & $40.0(22.6-58.6)$ \\
\hline Any living in same home & $58.3(39.9-74.4)$ & $62.9(44.8-80.2)$ \\
\hline Any left home within 3 years & $44.4(25.6-60.1)$ & $43.8(25.6-61.9)$ \\
\hline Grandparent $^{\dagger}$ & $16.7(2.1-26.5)$ & $40.1(22.6-58.6)$ \\
\hline Any grandchildren in same home & $5.6(-2.4-13.8)$ & $9.4(0-20.1)$ \\
\hline Any parent living ${ }^{\dagger}$ & $88.9(77.4-99.7)$ & $68.8(51.8-85.7)$ \\
\hline
\end{tabular}

*Values are percentages with 95\% confidence intervals in parentheses unless otherwise noted.

$\dagger \mathrm{p}<.05$.

${ }^{\ddagger} \mathrm{p}<.001$. 
Table 2. Medical and Reproductive Background*

\begin{tabular}{|c|c|c|}
\hline & $\begin{array}{l}\text { Whites } \\
(n=35)\end{array}$ & $\begin{array}{c}\text { African-Americans } \\
(n=33)\end{array}$ \\
\hline Hypertension ${ }^{\dagger}$ & $8.3(-1.1-17.8)$ & $40.6(22.6-58.6)$ \\
\hline Cardiovascular disease & $5.6(10.02-13.4)$ & $3.1(-3.2-9.5)$ \\
\hline Osteoporosis & 0.0 & $3.1(-3.2-9.5)$ \\
\hline Vascular thrombosis & $2.8(-2.9-8.4)$ & $3.1(-3.2-9.5)$ \\
\hline Ovarian cysts ${ }^{\S}$ & $27.8(12.4-43.1)$ & $6.3(3.2-15.1)$ \\
\hline Uterine fibroids ${ }^{\ddagger}$ & $30.6(14.7-46.4)$ & $62.5(45.8-80.2)$ \\
\hline Pelvic inflammatory disease & $2.8(-2.9-8.4)$ & $6.3(-2.6-15.1)$ \\
\hline Endometriosis & 0.0 & $3.1(-3.2-9.5)$ \\
\hline Tobacco, current & $16.7(3.9-29.5)$ & $15.6(2.3-28.9)$ \\
\hline Waist/hip ratio ${ }^{\dagger}$ & 0.77 (0.76-0.79) & $0.81(0.80-0.83)$ \\
\hline Age at menarche, years & $12.6(12.1-13.2)$ & $12.5(12.1-13.1)$ \\
\hline Avg cycle length, days & $30.9(27.5-34.3)$ & $28.4(27.6-29.3)$ \\
\hline Pregnancies, $n^{*}$ & $2.6(2.0-3.2)$ & $3.7(2.9-4.5)$ \\
\hline Menstrual irregularity, \% & $33.3(17.2-49.5)$ & $50.0(31.7-68.3)$ \\
\hline Age at onset, years & $46.1(44.9-47.3)$ & $45.3(43.9-46.6)$ \\
\hline
\end{tabular}

*Values are percentages with $95 \%$ confidence intervals in parentheses unless otherwise indicated.

${ }^{\dagger} \mathrm{p}<.005$.

${ }^{\ddagger} \mathrm{p}<.01$.

sp $<.05$.

adjustment for age, education, and income. Two items contributed most to this difference and reflect a more positive outlook toward the cessation of menses by the African-American women, i.e., "Absence of menses after the menopause is a relief" and "I look forward to not worrying about pregnancy after the menopause" (Table 3). The scores for the medical-intervention factor did not significantly differ between the two groups (mean ratings, 12.4 for African-Americans vs 10.8 for whites, $p=.09$ ), although there was a trend toward less favorable attitudes in white women with increasing education. Both groups rated psychosocial stressors as having slightly greater impact on well-being (mean ratings, 3.2 for African-Americans vs 3.3 for whites, $p=.7$ ) than physical symptoms. Adjustment for age, education, and income had no effect.

Mean values of follicular-phase plasma levels of estradiol, FSH, and DHEA-s, intercycle variation of these hormones, and rates of anovulatory cycles $(21.2 \%$ for African-Americans vs $28.6 \%$ for whites) as determined by luteal-phase progesterone were comparable in the two groups.

Factor analysis of the DSRs was performed using principal components analysis and varimax rotation, yielding four factors: psychological, mood, or memory changes; hot flashes or night sweats (vasomotor); genitourinary dryness (atrophic); and nonvasomotor or nonatropic physical complaints. Daily Symptom Ratings were similar in the two groups (Table 4). All of the women reported psychological problems at some point over the 2 months, although median scores suggest that most experienced only mild to moderate or infrequent symptoms. Most also reported nonvasomotor or nonatrophic physical symptoms. None of these factors would be considered specific to menopause, and given that hormonal levels of our subjects were all within premenopausal range, our findings are not surprising.

Although the prevalence of menopausal symptoms was similar in the two racial groups, more than two thirds of the white women reported discussing these symptoms with their physicians, while only one third of the AfricanAmerican women did (68.6\% vs $36.4 \%, p<.01)$. Comparable numbers of women in each group reported initiating the discussion; however, the white women were more than twice as likely as the African-American women to report that their physicians had inquired about symptoms (51.4\% vs $21.2 \% p<.01)$. Nearly one quarter of the white women had been recommended HRT, either for relief of atrophic or vasomotor symptoms $(8.3 \%)$ or for prevention of osteoporosis or cardiovascular disease $(17 \% ; 23 \%$ for either) versus none of the African-American women, for any reason ( $23 \%$ vs $0 \%, p<.005)$. Despite these apparent differences, there was no significant difference in the women's levels of satisfaction regarding medical attention to the menopause. 
Table 3. Menopause Attitudes Scale*

\begin{tabular}{|c|c|c|}
\hline & $\begin{array}{l}\text { Whites } \\
(n=35)\end{array}$ & $\begin{array}{l}\text { African-Americans } \\
(n=33)\end{array}$ \\
\hline \multicolumn{3}{|l|}{ Medical intervention } \\
\hline Menopause is a change of life that should be treated medically... & $3.7(31 .-4.2)$ & $4.1(3.4-4.7)$ \\
\hline Problems in menopause will disappear... and should not be treated ${ }^{\dagger}$ & $5.5(5.0-5.9)$ & $4.8(4.2-5.5)$ \\
\hline Natural approaches...for menopause symptoms are better than hormone... ${ }^{\dagger}$ & $3.4(2.8-3.9)$ & $2.8(2.8-3.4)$ \\
\hline Women are less sexually attractive after... ${ }^{\dagger}$ & $5.6(5.0-6.2)$ & $6.2(5.8-6.7)$ \\
\hline A woman feels like less of a woman following menopause. ${ }^{\dagger}$ & $5.7(5.1-6.3)$ & $5.7(5.1-6.2)$ \\
\hline The absence of menses after menopause is a relief. ${ }^{\ddagger}$ & $2.7(2.0-3.5)$ & $1.8(1.3-2.3)$ \\
\hline Menopause causes unpleasant symptoms. ${ }^{\dagger}$ & $3.0(2.6-3.5)$ & $3.2(2.8-3.7)$ \\
\hline After menopause, sex is more enjoyable. & $3.6(3.3-3.9)$ & $3.6(3.2-4.0)$ \\
\hline
\end{tabular}

*Items are rated 1 (strongly agree) to 7 (strongly disagree); lower overall scores indicate more positive attitudes; 95\% confidence intervals are in parentheses.

${ }^{\dagger}$ Individual scores are reversed for calculation of overall score.

${ }^{\ddagger} \mathrm{p}<.05$.

The white women were more likely to have seen their physician within the last year $(91 \%$ of white women vs $73 \%$ of African-American women, $p<.05$ ); however, the African-American women were equally likely to have undergone a gynecologic examination within 1 year $(75 \%$ of Caucasian women vs $69 \%$ of African-American women). There were no significant differences between the racial groups in gender of provider.

The greatest proportions of women in both samples cited books and periodicals as their primary source of menopause-related information (37\% of African-American vs $67 \%$ of whites, $p<.05$ ); however, the African-American women were eight times as likely as the white women to cite family as their primary source of menopause-related information $(22.8 \%$ vs $2.8 \%$, respectively; $p<.05)$. Although a greater proportion of the African-American women tended to cite their physician as their primary source of information ( $17 \%$ vs $3 \%$ ), larger numbers from each racial group reported that their physicians offered no information at all (60\% African-Americans vs $42 \%$ whites).

\section{DISCUSSION}

Reproductive hormone levels were similar and solidly within premenopausal range for the two racial groups. The greater BMIs and android fat distribution of the African-Americans did not appear to affect rates of reporting of perimenopausal symptoms, as these were comparable.

Overall, African-American women viewed the menopause more positively than did white women, despite reporting symptoms similar in degree and frequency. This conflicts with some previous reports that women with lower incomes have more negative attitudes toward menopause. ${ }^{11,42}$ However, others have suggested that AfricanAmerican families interact within their kinship network to a greater extent, ${ }^{43}$ and that extended family systems are

Table 4. Daily Symptom Ratings*

\begin{tabular}{|c|c|c|}
\hline Daily Symptoms & $\begin{array}{l}\text { Whites } \\
(n=34)\end{array}$ & $\begin{array}{l}\text { African-Americans } \\
(n=33)\end{array}$ \\
\hline DSR total score & $154.9(112.8-197.1)$ & $158.7(106.6-202.0)$ \\
\hline Factor 2: hot flashes, sweats & $\begin{array}{c}9.9(2.5-17.9) \\
46 \%\end{array}$ & $\begin{array}{c}8.8(1.7-15.4) \\
45 \%\end{array}$ \\
\hline Factor 4: aches, bloating & $\begin{array}{c}29.0(20.9-24.0) \\
91 \%\end{array}$ & $\begin{array}{c}33.5(24.4-41.0) \\
97 \%\end{array}$ \\
\hline
\end{tabular}

*Differences in scores were not statistically significant $(\mathrm{p}<.05) ; 95 \%$ confidence intervals are in parentheses. Percentages reflect those symptomatic during the course of the study. 
related to improved status or ability to cope with stressors in middle age..$^{9,21}$

Meanwhile, the African-American women viewed medical intervention consistently neutrally to slightly negatively and appeared equally satisfied with their health care in spite of an absence of discussion of symptoms or of HRT. Alternatively, this disinterest in medical intervention may have resulted in recall bias against reporting of such discussion. This disinterest was borne out in subsequent focus groups with women of similar characteristics. ${ }^{44}$ It is also supported by several studies of patient expectations demonstrating that prevention issues are of lowest priority to patients, that physicians prescribe medications more frequently than patients expect or desire, ${ }^{45}$ and that among nonwhite patients with fewer years of education, more technical elements (physical examination, laboratory testing) are expected than psychosocial elements (counseling, preventive measures). ${ }^{46}$

In contrast, one quarter of the white women had been offered HRT, but their attitudes toward medical intervention tended to be less favorable with increasing education; our findings are limited by the fairly homogeneously welleducated sample. Some studies suggest that college-educated women are more likely to attribute psychological symptoms to life stressors than a biomedical model and prefer "natural therapy" to HRT ${ }^{30}$; that they are more concerned about the potential risk of breast cancer than of heart disease, and rate their risk of breast cancer far higher $^{27}$; and that perceived risk of malignancy plays a much greater role in women's decisions about HRT than perceived risk of menopause-related sequelae. ${ }^{47}$ The latter was corroborated in focus groups. ${ }^{44}$ Still others report a positive correlation between education level and acceptance of HRT. ${ }^{30,31}$ Sample differences might explain this apparent incongruity.

These findings suggest that African-American women and white women have different expectations of symptoms, long-term sequelae and their susceptibility to them, and the role of HRT. Less than 5\% of the volunteers for the study were excluded for current hormone use; therefore, exclusion of women who used HRT should not have introduced significant bias. We had not addressed possible differences in type of provider (internist vs gynecologist, academic center vs community) in this study (although we did in subsequent focus groups and found none); this may account for some of the attitude differences. However, physicians appear to have played little role in menopause education or counseling for the women in our sample.

This study was conducted as a preliminary investigation, and results cannot be generalized to all women. The sample sizes were small, and the two racial group were relatively homogeneous in education and income; thus, absence of associations with education and income are not definitive. Nonetheless, the results from this nonclinical, community-based sample of convenience suggest the importance of further study, particularly of the psycho- social and cultural determinants of women's health and behavior in the late reproductive years. We expect that a similar investigation of a broader, more diverse, communitybased sample already under way will clarify these findings.

We express our thanks to Lisa Sheehe, BSN, Mary Jane Murphy, RN, Beatriz Garcia-Espana, MS, and Andrew Cucchiara, MS, for their technical assistance.

\section{REFERENCES}

1. Toner JP. Defining Poor Responders. AFS Postgraduate ART Course. Jones Institute for Reproductive Medicine, Norfolk, Va, Eastern Virginia Medical School; 1993.

2. Sherman BM, West JH, Korenman SG. The menopausal transition: analysis of LH, FSH, estradiol, and progesterone concentrations during menstrual cycles of older women. J Clin Endocrinol Metab. 1976;42:629-36.

3. Richardson SJ, Senikas V, Nelson JF. Follicular depletion during the menopausal transition: evidence for accelerated loss and ultimate exhaustion. J Clin Endocrinol Metab. 1987;65:1231-7.

4. Myers LS, Dixen J, Morrissette D, Carmichael M, Davidson JM. Effects of estrogen, androgen and progestin on sexual psychophysiology and behavior in postmenopausal women. J Clin Endocrinol Metab. 1990;70:1124-31.

5. Folsom AR, Burke Gl, Byers CL, et al. Implications of obesity for cardiovascular disease in blacks: the CARDIA and ARIC studies. Am J Clin Nutr. 1991;53:1604S-11S.

6. Keenan NL, Strogatz DS, James SA, Ammerman AS, Rice BL. Distribution and correlates of wast-to-hip ratio in black adults: the Pitt County study. Am J Epidemiol. 1992;135:678-84.

7. Farmer ME, White LR, Broday JA, Bailey KR. Race and sex differences in hip fracture incidence. Am J Public Health 1984; 74: 1274-80.

8. Kellie SE, Brody JA. Sex-specific and race-specific hip fracture rates. Am J Public Health 1990;80:326-8.

9. Standing TS, Glazer B, Attitudes of low-income clinic patients toward menopause. Health Care Wom Int. 1992;13:271-80.

10. Frey KA. Middle-aged women's experience and perceptions of menopause. Wom Health 1981;6:25-36.

11. Dege K, Gretzinger J. Attitudes of families toward menopause. In: Voda AM, Dinnerstein M, O’Donnell SR, eds. Changing Perspectives on Menopause. Austin, Tex: University of Texas Press; 1982:60-9.

12. Jaszmann LJ. Epidemiology of the climacteric syndrome. In: Campbell S. ed. The Management of the Menopause and Postmenopausal Years. Baltimore, Md: University Park Press; 1976.

13. Avis NE, McKinlay SM. A longitudinal analysis of women's attitudes toward the menopause: results from the Massachusetts Women's Health Study. Maturitas. 1991;13:65-79.

14. Utian WH, Schiff I. NAMS-Gallup survey on women's knowlege, information sources, and attitudes to menopause and hormone replacement therapy. Menopause: J N Am Menopause Soc. 1994; 1:39-48.

15. Utian WH. Menopause in Modern Perspective. New York, NY: Prentice-Hall, Inc.; 1980.

16. Griffen J. Cultural models for coping with menopause. In: Voda AM, Dinnerstein M, O'Donnell SR, editors. Changing Perspectives on Menopause. Austin, Tex: University of Texas Press; 1982:248.

17. Flint M. Male and female menopause: a cultural put-on. In: Voda AM, Dinnerstein M, O'Donnell SR, editors. Changing Perspectives on Menopause. Austin, Tex. University of Texas Press; 1982:363.

18. Flint M. Cross-cultural factors that affect age of menopause. In: Van Keep PA, Greenblatt RB, Albeaus-Fernet M, editors. Consensus on Menopause Research. Proceedings of the First International Congress on the Menopause; June, 1976. Baltimore, Md.: University Park Press; 1976:73. 
19. Flint M. The menopause: reward or punishment? Psychosomatics. 1975; 16:161-3.

20. Brown JK. A cross-cultural exploration of the end of the childbearing years. In: Voda AM, Dinnerstein M, O’Donnell SR, editors. Changing Perspectives on Menopause. Austin, Tex.: University of Texas Press; 1982:51.

21. Robins LN, Regier DA, editors. Psychiatric Disorders in America: the Epidemiologic Catchment Area Study. New York, NY: The Free Press/Macmillan, Inc.; 1991.

22. Bart P, Grossman M. Menopause. In: Notman M, Nodelson C, editors. The Woman Patient. New York, NY: Plenum; 1978:354-7.

23. Fox-Young S, Sheehan M, O’Connor V, Cragg C, Del Mar C. Women's perceptions and experience of menopause: a focus group study. J Psychosom Obstet Gynecol. 1995;16:215-21.

24. Fox-Young S, Cragg C. Do psycho-social factors contribute more to symptom reporting by middle-aged women than hormonal status? Maturitas. 1995;20:63-9.

25. Harris RB, Laws A, Reddy VM, King A, Haskell WL. Are women using postmenopausal estrogens? A community survey. Am J Public Health. 1990;80:1266-8.

26. Hemminki E, Malin M, Topo P. Selection to postmenopausal therapy by women's characteristics. J Clin Epidermiol. 1993;46:211-9.

27. Pilote L, Hlatky MA. Attitudes of women toward hormone therapy and prevention of heart disease. Am Heart J. 1995;129:1237-8.

28. Schmitt N, Gogate J, Rothert M, et al. Capturing and clustering women's judgment policies: the case of hormonal therapy for menopause. J Gerontol. 1991;46:92-101.

29. Sinclair JK, Bond CM, Taylor RJ. Hormone replacement therapy: a study of women's knowledge and attitudes. Br J Gen Pract. 1993;43:365-70.

30. Derby CA, Hume AL, Barbour MM, McPhillips JB, Lasater TM, Carleton RA. Correlates of postmenopausal estrogen use and trends through the 1980s in two southeastern New England communities. Am J Epidemiol. 1993;137:1125-35.

31. Egeland GM, Matthews KA, Kuller LH, Kelsey, SF. Characteristics of noncontraceptive hormone users. Prev Med. 1988;17: 403-22.

32. Ware JE, Snow KK, Kosinski M, Gandek B. SF-36 Health Survey Manual and Interpretation Guide. Boston, Mass: The Health Institute. New England Medical Center; 1993.

33. McHorney CA, Ware JE, Raczek AE. The MOS 36-item short-form health survey (SF-36), II: pychometric and clinical tests of validity in measuring physical and mental health constructs. Med Care. 1993:31:247-63.

34. How to Score the SF-36 Health Survey. Boston, Mass: The Medical Outcomes Trust: 1993.

35. Radloff LS. The CES-D scale: a self-report depression scale for research in the general population. Appl Psychol Measurement. 1977:1:385-401.

36. Endicott J, Nee J, Harrison W, Blumenthal R. Quality-of-life enjoyment and satisfaction questionnaire-a new measure. Psychopharmacol Bull. 1993;29:321-6.

37. Leiblum SR, Swartzman LC. Women's attitudes toward the menopause: an update. Maturitas. 1986;8:47-56.

38. Groeneveld FPMJ, Bareman FP, Barentsen K, Dokter HJ, Drogendijk AC, Hoes AW. Relationships between attitude towards menopause, well-being and medical attention among women aged 45-60 years. Maturitas. 1993;17:77-88.

39. Garrow JS, Webster J. Quetelet's index $\left(\mathrm{W} / \mathrm{H}^{2}\right)$ as a measure of fatness. Int J Obes. 1985;9:147-53.

40. Hartz AJ, Rupley DC, Rimm AA. The association of girth measurements with disease in 32,856 women. Am J Epidemiol. 1984; 119: 71-80.

41. Freeman EW, DeRubeis RJ, Rickels K. Reliability and validity of a daily diary for premenstrual syndrome. Psychol Res. 1996;65:97-106.

42. Mitchell JS, Register JC. An exploration of family interaction among the elderly by race, socioeconomic status, and residence. Gerontologist. 1984;24:48-54.

43. Van Keep P, Kellerhals J. The impact of sociocultural factors on symptom formation. Psychother Psychosom. 1974;23:251-263.

44. Pham KC, Freeman EW, Grisso JA. Menopause and hormone replacement therapy: focus groups of afro-american and caucasian women. Menopause. In press.

45. Sanchez-Menegay C, Stalder H. Do physicians take into account patients' expectations? J Gen Int Med 1994;9:404-6.

46. Kravitz RL, Cope DW, Bhrany V, Leake B, Internal medicine patients' expectations of care during office visits. J Gen Intern Med. 1994;9:75-81.

47. Logethetis ML. Women's decisions about estrogen replacement therapy. West Nurs Res. 1991;13:458-74. 